\title{
IONIC INTERACTIONS IN CROSS-LINKED POLY(VINYL ALCOHOL) HYDROGEL BLENDED WITH STARCH
}

\author{
Zain Ul ABDEEN* and Rehana SAEED \\ Department of Chemistry, University of Karachi, 75270 Karachi, Pakistan
}

Polymeric hydrogels having ions captivating sites serve as a good conductive source and are widely utilized for many applications. Adsorption of alkali and alkaline metal ions was studied using poly(vinyl alcohol) hydrogels cross-linked with borax. Adsorption isotherms were used to investigate the mode of interaction

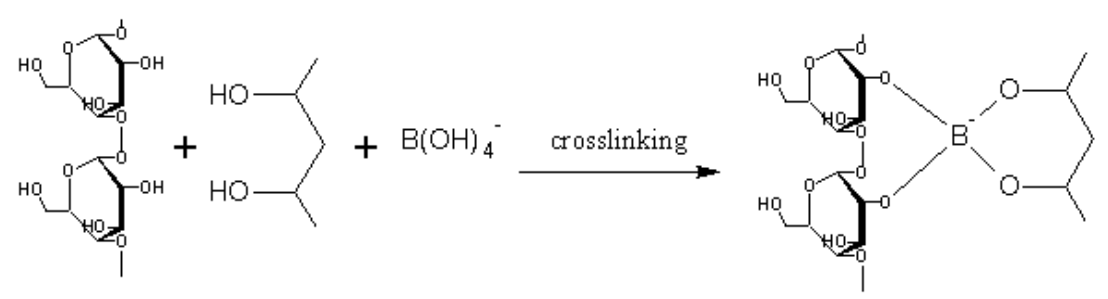
and assimilation of ions through hydrogel

system with and without the involvement of starch at $303 \mathrm{~K}$. The applicability of isotherms was tested based on statistical evaluations using

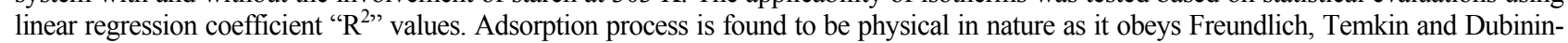
Radushkevich isotherms. The adsorption takes place in pores of hydrogel. Ionic interactions between metal ions and hydrogel units were also observed. FTIR analysis of hydrogels was carried out for confirmation of interaction between metal ions and hydrogel.

\section{INTRODUCTION}

Polymeric hydrogels are magnificent materials due to the water holding and releasing abilities; upon variation in external stimuli. The modification in the composition of hydrogels by blending and cross-linking makes them suitable source for the transportation of ionic species. There are wide applications of hydrogels incorporating poly(vinyl alcohol) and starch, in the field of agricultural, electrical and medical sciences. Starch is a polysaccharide composed of numbers of glucose units joined via 1,4-glycosidic linkages. Starch is cheap, naturally available, non-toxic and biodegradable material, known due to its adhesiveness and gluing ability. ${ }^{1}$ Indulging starch with poly(vinyl alcohol) (PVOH) brings the modification in mechanical ability, gelatin ability, and biodegradability of PVOH-Starch blend. ${ }^{2,3}$ For specified applications, further enhancement in the properties of PVOH-Starch blend was needed, with the incorporation of plasticizers; 1,4- butandiol, 1,2,6hexanetriol, pentaerythritol, xylitol, mannitol were found to enhanced thermal stability. ${ }^{4}$ Maltitol, sorbitol, and glycerol enhanced chain mobility and blend processability. ${ }^{5}$ The involvement of crosslinkers; like citric acid and formaldehyde showed non toxicity, epichlorohydrin enhanced flexibility and borate increased the mechanical ability. ${ }^{6}$ The biodegradability found to decrease upon crosslinking.

For the polymers having hydroxyl moiety in the molecular structure, borax was used as crosslinker. ${ }^{7}$ Borax has an ability to interact with hydroxyl group in the formation of cross-linked units between chains of polysaccharides. ${ }^{8,9} \mathrm{PVOH}-$ Starch borate hydrogel is formed due to interaction of borax with hydroxyl groups present in both

\footnotetext{
${ }^{*}$ Corresponding author: zain_chm@yahoo.com
} 
PVOH and starch. ${ }^{10,11}$ Similar interactions between the hydroxyl groups in cellulose and $\mathrm{PVOH}$ with borate ions were available in the literature. ${ }^{12,13}$ Water holding ability of hydrogel and the presence of $\mathrm{BO}_{4}^{-}$in cross-linked PVOH-Starch make it attractive for the maintenance and release of ionic substances, making it suitable for external drug delivery for wounds via bandages ${ }^{14,15}$ and use as a controlled release system for agricultural needs. ${ }^{16}$ The present study was designed by focusing the ion-capture ability of PVOH-Starch borate hydrogel system, which concerned with the analysis of adsorption isotherms for alkali and alkaline metal chlorides through hydrogel system.

\section{RESULTS AND DISCUSSION}

\section{Adsorbed amount}

Adsorption of lithium, sodium, potassium, magnesium and calcium chloride was carried out using PVOH-borate and PVOH-Starch borate hydrogel. The data obtained were used to study adsorption isotherms. The amount of alkali and alkaline metal chlorides adsorbed in $\mathrm{PVOH}$ hydrogel were determined using the relation (1).

$$
q=\frac{V}{M}\left(C_{i}-C_{e}\right)
$$

where: "q" is the amount of electrolyte adsorbed, "V" is the volume of electrolyte, " $\mathrm{M}$ " is mass of PVOH hydrogel, " $\mathrm{C}_{\mathrm{i}}$ and $\mathrm{C}_{\mathrm{e}}$ " are concentrations of electrolyte present initially and after adsorption. It was observed that the amount of adsorbed electrolyte increased on enhancing the initial concentration of metal ion solution. Indulgence of starch also favored the adsorption of metal ions in hydrogel moiety. The results were tabulated in Table 1.

\section{Freundlich isotherm}

The nature and involvement of ions interactions during sorption process was analyzed by the amount of adsorbed electrolyte and used to validate various isotherms on adsorption process. ${ }^{17}$

Freundlich isotherm represents both physicosorption and chemisorption phenomenon on the heterogeneous surface of the adsorbent. Freundlich adsorption isotherm is represented as (2),

$$
\ln q_{e}=\ln k_{f}+\frac{1}{n} \ln C_{e}
$$

where: " $\mathrm{q}_{\mathrm{e}}$ " is the amount of ions adsorbed at equilibrium, " $\mathrm{C}$ " " is the concentration of ions at equilibrium. " $\mathrm{k}_{\mathrm{f}}$ " and " $\mathrm{n}$ " are Freundlich isotherm constants, representing the sorption capacity and the sorption intensity. $\mathrm{R}^{2}$ values for Freundlich isotherm are approaching unity, therefore, adsorption of electrolytes in PVOH hydrogels obeys the Freundulich adsorption isotherm. Involvement of starch in $\mathrm{PVOH}$ hydrogel enhanced the adsorption capacity of ions. The adsorption capacity of monovalent electrolytes in $\mathrm{PVOH}-$ Starch borate hydrogel was found to be in order $\mathrm{KCl}>\mathrm{NaCl}>\mathrm{LiCl}$ and divalent electrolytes in order $\mathrm{CaCl}_{2}>\mathrm{MgCl}_{2}$ which showed that the involvement of starch favored the adsorption of large cations in PVOH hydrogel which focused the availability of large pore sizes in comparison with PVOH-borate hydrogels. The increased value of adsorption intensity revealed that adsorption of electrolytes is more favorable in $\mathrm{PVOH}-\mathrm{Starch}$ borate hydrogel. The adsorption capacity of monovalent cations in hydrogel was found to be greater than that of divalent cations. This is due to the fact that hydrogel has $\mathrm{BO}_{4}{ }^{-}$units which have different mode of interaction for various cations. Monovalent cations interacted directly with $\mathrm{BO}_{4}^{-}$ units in ratio of $1: 1$ as $\mathrm{BO}_{4}^{-} \ldots \mathrm{M}^{+}$while, divalent cations associate two $\mathrm{BO}_{4}^{-}$units in ratio $1: 2$ as $\left(\mathrm{BO}_{4}^{-}\right)_{2} \ldots \mathrm{M}^{2+}$ resulting in lesser adsorption capacity by bridging cross-linked units which shrink PVOH hydrogels causing reduction in volume and pore size of hydrogel. The adsorption capacity $\left(\mathrm{k}_{\mathrm{f}}\right)$ and intensity (n) for each electrolyte adsorbed in PVOH hydrogels are shown in Table 2. The plot lnq vs $\operatorname{lnC}$ for Freundlich isotherm is given in Figure 1.

\section{Langmuir isotherm}

Langmuir isotherm relates to the chemisorption process on the homogenous surface of adsorbent represented by the relation (3),

$$
\frac{C_{e}}{q_{e}}=\frac{C_{e}}{q_{m}}+\frac{1}{K_{L} q_{m}}
$$

where: " $\mathrm{q}_{\mathrm{m}}$ " and " $\mathrm{K}_{\mathrm{L}}$ " are the Langmuir adsorption constants representing the maximum adsorption capacity and the affinity of binding sites, respectively. The Langmuir's adsorption isotherm showed deviations in $\mathrm{R}^{2}$ values from unity, for the adsorption of electrolytes in PVOH-Starch borate hydrogels. 
Table 1

Amount of electrolyte adsorbed in PVOH hydrogels at $303 \mathrm{~K}$

\begin{tabular}{|c|c|c|c|c|c|}
\hline [Electrolyte] & \multicolumn{5}{|c|}{ Amount adsorbed $\left(\mathrm{mg} \cdot \mathrm{g}^{-1}\right)$} \\
\hline$\left(\right.$ g. $\left.\mathrm{L}^{-1}\right)$ & $\mathrm{LiCl}$ & $\mathrm{NaCl}$ & $\mathrm{KCl}$ & $\mathrm{MgCl}_{2}$ & $\mathrm{CaCl}_{2}$ \\
\hline \multicolumn{6}{|c|}{ PVOH-borate hydrogel } \\
\hline 20 & 97.65 & 84.87 & 73.95 & 40.43 & 36.78 \\
\hline 30 & 145.3 & 131.2 & 110.9 & 68.44 & 58.90 \\
\hline 40 & 169.3 & 157.7 & 135.8 & 88.39 & 79.89 \\
\hline 50 & 198.4 & 183.8 & 175.4 & 114.4 & 102.6 \\
\hline 60 & 252.1 & 235.1 & 221.8 & 143.7 & 132.6 \\
\hline 70 & 296.4 & 256.4 & 238.7 & 177.4 & 158.4 \\
\hline 80 & 339.4 & 292.4 & 262.9 & 200.4 & 180.6 \\
\hline \multicolumn{6}{|c|}{ PVOH-Starch borate hydrogel } \\
\hline 20 & 101.6 & 107.8 & 110.9 & 49.43 & 55.78 \\
\hline 30 & 151.3 & 159.2 & 162.9 & 81.44 & 88.90 \\
\hline 40 & 177.3 & 184.7 & 191.3 & 106.4 & 114.7 \\
\hline 50 & 222.3 & 232.4 & 242.6 & 136.4 & 143.9 \\
\hline 60 & 264.1 & 276.1 & 286.8 & 169.7 & 177.6 \\
\hline 70 & 310.4 & 329.4 & 332.4 & 208.4 & 215.7 \\
\hline 80 & 355.4 & 363.4 & 379.8 & 234.4 & 242.6 \\
\hline
\end{tabular}

Table 2

Freundlich adsorption isotherm parameters

\begin{tabular}{c|c|c|c}
\hline Electrolytes & $\begin{array}{c}\mathrm{K}_{\mathrm{f}} \\
\left(\mathrm{mg.g}^{-1}\right)\end{array}$ & $\begin{array}{c}\mathrm{n} \\
--\end{array}$ & $\begin{array}{c}\mathrm{R}^{2} \\
--\end{array}$ \\
\hline \multicolumn{4}{c}{ PVOH-borate hydrogel } \\
\hline $\mathrm{LiCl}$ & 6.995 & 1.141 & 0.987 \\
$\mathrm{NaCl}$ & 6.385 & 1.147 & 0.992 \\
$\mathrm{KCl}$ & 4.525 & 1.070 & 0.993 \\
$\mathrm{MgCl}_{2}$ & 1.314 & 0.871 & 0.997 \\
$\mathrm{CaCl}_{2}$ & 1.140 & 0.864 & 0.990 \\
\hline \multicolumn{4}{c}{$\mathrm{PVOH}-\mathrm{Starch}$ borate hydrogel } \\
\hline $\mathrm{LiCl}_{\mathrm{NaCl}}^{\mathrm{KCl}}$ & 7.245 & 1.132 & 0.997 \\
$\mathrm{KCl}^{\mathrm{MgCl}}$ & 7.760 & 1.371 & 0.996 \\
$\mathrm{CaCl}_{2}$ & 7.988 & 1.141 & 0.995 \\
\hline
\end{tabular}

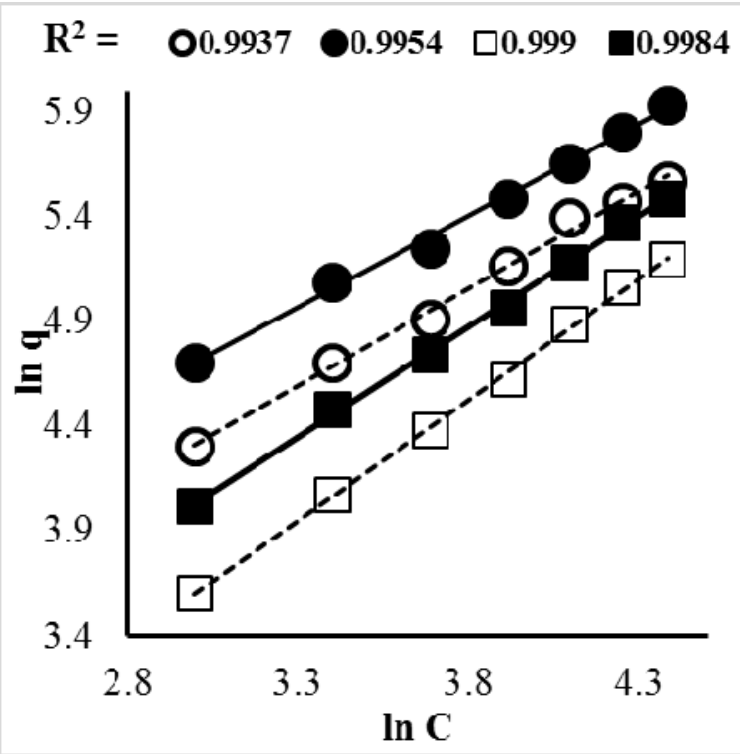

Fig. 1 - Representative plot for Freundlich adsorption isotherm for $\mathrm{KCl}$ in $\mathbf{O} \mathrm{PVOH}-$ borate,

- PVOH-Starch borate and $\mathrm{CaCl}_{2}$ in $\square \mathrm{PVOH}$-borate, a PVOH-Starch borate hydrogel at $303 \mathrm{~K}$. 


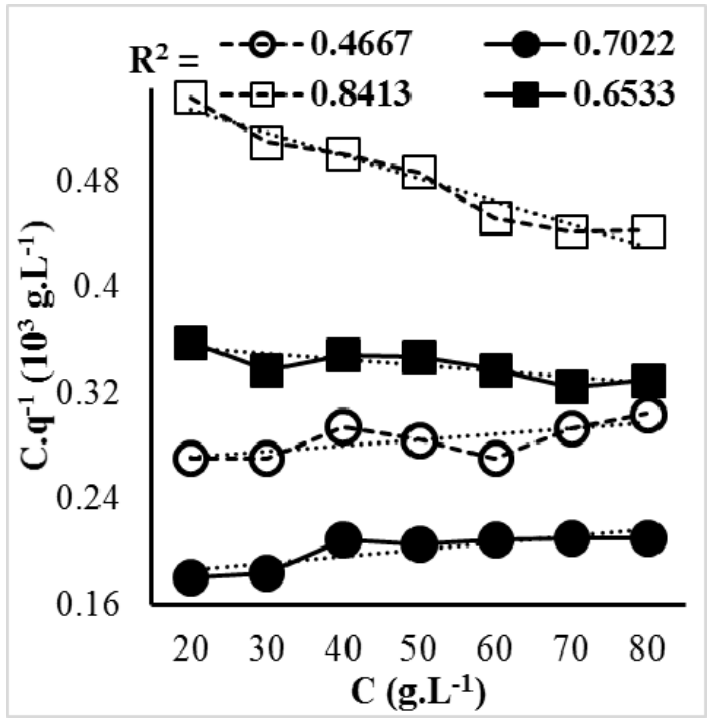

Fig. 2 - Representative plot for Langmuir adsorption isotherm for $\mathrm{KCl}$ in $\mathbf{O} \mathrm{PVOH}-$ borate,

- PVOH-Starch borate hydrogel \& $\mathrm{CaCl}_{2}$ in $\square \mathrm{PVOH}$-borate, - PVOH-Starch borate hydrogel at $303 \mathrm{~K}$.

The representative plot for Langmuir isotherm is shown in Figure 2. The adsorption process does not obey the Langmuir isotherm and following Freundlich isotherm to a greater extent indicated that the adsorption of electrolytes in PVOH-Starch borate hydrogel is a physicosorption phenomenon.

\section{Isotherms supporting physicosorption}

Temkin and Dubinin-Radushkevich (D-R) isotherms supported the physical nature of adsorption and explained the mechanism involved in physicosorption. Obeying Temkin isotherms showed that physicosorption is due to an interaction between metal ions and $\mathrm{PVOH}$ hydrogels and D-R isotherms portray physicosorption with the pore-filling mechanism on the adsorbent surface. Temkin and D-R isotherms were presented in relations 4 and 5 , respectively.

$$
\begin{gathered}
q_{e}=\frac{R T}{b} \ln K_{T}+\frac{R T}{b} \ln C_{e} \\
\ln q_{e}=\ln q_{d}-\beta R^{2} T^{2} \ln \left[1+\frac{1}{C_{e}}\right]^{2}
\end{gathered}
$$

where: " $\mathrm{q}_{\mathrm{e}}$ " is the amount of ions adsorbed at equilibrium, " $\mathrm{R}$ " is molar gas constant, " $T$ " is temperature, " $b$ " is Temkin isotherm constant, and " $\mathrm{K}_{\mathrm{T}}$ " is Temkin isotherm constant representing equilibrium binding of adsorbate. " $q_{d}$ " is D-R isotherm constant which portrays theoretical saturation capacity of sorbate and " $\beta$ " is free energy constant. For evaluating Temkin isotherm, the graphs between $\mathrm{q}_{\mathrm{e}}$ and $\operatorname{lnC}_{\mathrm{e}}$ were plotted; constants " $\mathrm{b}$ " and " $\mathrm{K}_{\mathrm{T}}$ " were calculated from the slope and intercept of plots. The heat of electrolyte adsorption per mole of hydrogel was calculated based on values of constant " $b$ " using relation. It was found to be lesser than $20 \mathrm{~kJ} \cdot \mathrm{mol}^{-1}$, which confirmed that process is physicosorption. ${ }^{18,19}$ The heat energy of electrolyte per mole of hydrogel was increased on the inclusion of starch in hydrogel. The presence of more water molecules in hydrogel moiety utilized more energy for substitution of water molecules with cations in pores of PVOH-Starch borate hydrogel. Temkin isotherm parameters are shown in Table 3.

Free energy is derived from D-R isotherm using relation and has value lesser than $8 \mathrm{~kJ} \cdot \mathrm{mol}^{-1}$ confirming physical nature of adsorption. ${ }^{18,19}$ Starch enhanced the saturation capacity of PVOHborate hydrogel and found to be greater for potassium ions due to large cationic radius among other ions. D-R adsorption isotherm parameters are given in Table 4.

\section{FTIR analysis of hydrogels}

FTIR elucidation of the aqueous PVOH-Starch blend, PVOH-Starch borate hydrogel, and $\mathrm{K}^{+}, \mathrm{Ca}^{2+}$ adsorbed $\mathrm{PVOH}-\mathrm{Starch}$ borate hydrogel confirmed the crosslinking between polymers and $\mathrm{BO}_{4}{ }^{-}$units and association of $\mathrm{K}^{+}$and $\mathrm{Ca}^{2+}$ in $\mathrm{PVOH}-\mathrm{Starch}$ borate hydrogel moiety. The attributions of different peaks in FTIR spectra are given in Table 5. FTIR spectra are shown in Figure 3. The peak obtained in region $1382-1384 \mathrm{~cm}^{-1}$ confirmed the association between hydroxyl groups of polymers and $\mathrm{BO}_{4}^{-}$units in a tetrahedral fashion. ${ }^{20}$ The disappearance of the peak in region 2079-2088 $\mathrm{cm}^{-1}$ 
which was assigned to the liberation of free water molecules also confirmed the binding of polymers with cross-linker. The values of $\mathrm{C}-\mathrm{O}$ stretching vibrations were found increased upon adsorption of cations. $\mathrm{M}-\mathrm{O}-\mathrm{H}$ stretching vibrations appeared in spectrum of electrolyte adsorbed hydrogel. The interaction of cations in hydrogel moiety was confirmed from the elucidations of stretching $\mathrm{C}-\mathrm{O}$ and appearance of M-O-H peaks. ${ }^{21}$

Table 3

Temkin adsorption isotherm parameters

\begin{tabular}{|c|c|c|c|c|}
\hline Electrolytes & $\begin{array}{c}\mathrm{K}_{\mathrm{T}} \\
\left(\mathrm{L} \cdot \mathrm{g}^{-1}\right)\end{array}$ & $\begin{array}{l}\mathrm{b} \\
-\end{array}$ & $\begin{array}{c}\text { B } \\
\left(\mathrm{J} \cdot \mathrm{mol}^{-1}\right)\end{array}$ & $\begin{array}{c}\mathrm{R}^{2} \\
-\end{array}$ \\
\hline \multicolumn{5}{|c|}{ PVOH-borate hydrogel } \\
\hline $\begin{array}{c}\mathrm{LiCl} \\
\mathrm{NaCl} \\
\mathrm{KCl} \\
\mathrm{MgCl}_{2} \\
\mathrm{CaCl}_{2}\end{array}$ & $\begin{array}{l}0.0782 \\
0.0812 \\
0.0757 \\
0.0619 \\
0.0614\end{array}$ & $\begin{array}{l}14.941 \\
17.182 \\
17.896 \\
21.938 \\
24.178\end{array}$ & $\begin{array}{l}168.60 \\
146.61 \\
140.76 \\
114.83 \\
104.19\end{array}$ & $\begin{array}{l}0.930 \\
0.962 \\
0.966 \\
0.943 \\
0.945\end{array}$ \\
\hline \multicolumn{5}{|c|}{ PVOH-Starch borate hydrogel } \\
\hline $\begin{array}{c}\mathrm{LiCl} \\
\mathrm{NaCl} \\
\mathrm{KCl} \\
\mathrm{MgCl}_{2} \\
\mathrm{CaCl}_{2}\end{array}$ & $\begin{array}{l}0.0780 \\
0.0782 \\
0.0794 \\
0.0633 \\
0.0712\end{array}$ & $\begin{array}{l}14.144 \\
13.460 \\
13.264 \\
18.910 \\
20.512\end{array}$ & $\begin{array}{l}178.10 \\
187.15 \\
189.92 \\
133.21 \\
122.81\end{array}$ & $\begin{array}{l}0.949 \\
0.952 \\
0.951 \\
0.947 \\
0.951\end{array}$ \\
\hline
\end{tabular}

Table 4

Dubinin-Radushkevich adsorption isotherm parameters

\begin{tabular}{|c|c|c|c|c|}
\hline Electrolytes & $\begin{array}{c}\mathrm{q}_{\mathrm{d}} \\
\left(\mathrm{mg} \cdot \mathrm{g}^{-1}\right)\end{array}$ & $\begin{array}{c}\beta \times 10^{6} \\
\left(\mathrm{~mol}^{2} \mathrm{~J}^{-2}\right)\end{array}$ & $\begin{array}{c}\mathrm{E} \\
\left(\mathrm{J} . \mathrm{mol}^{-1}\right)\end{array}$ & $\mathrm{R}^{2}$ \\
\hline \multicolumn{5}{|c|}{ PVOH-borate hydrogel } \\
\hline $\mathrm{LiCl}$ & 435.19 & 2.560 & 441.88 & 0.929 \\
\hline $\mathrm{NaCl}$ & 393.46 & 2.584 & 439.83 & 0.961 \\
\hline $\mathrm{KCl}$ & 374.61 & 2.766 & 425.10 & 0.960 \\
\hline $\mathrm{MgCl}_{2}$ & 297.97 & 3.392 & 383.90 & 0.960 \\
\hline $\mathrm{CaCl}_{2}$ & 269.18 & 3.411 & 382.85 & 0.957 \\
\hline \multicolumn{5}{|c|}{ PVOH-Starch borate hydrogel } \\
\hline $\mathrm{LiCl}$ & 464.98 & 2.599 & 438.55 & 0.945 \\
\hline $\mathrm{NaCl}$ & 485.33 & 2.582 & 440.03 & 0.936 \\
\hline $\mathrm{KCl}$ & 498.19 & 2.572 & 440.92 & 0.946 \\
\hline $\mathrm{MgCl}_{2}$ & 345.84 & 3.309 & 388.69 & 0.961 \\
\hline $\mathrm{CaCl}_{2}$ & 347.58 & 3.112 & 400.58 & 0.961 \\
\hline
\end{tabular}

Table 5

Peak assignment of adsorption in $\mathrm{PVOH}-\mathrm{Starch}$ borate hydrogels

\begin{tabular}{|c|c|c|c|c|c|}
\hline $\begin{array}{c}\text { Aqueous } \\
\text { PVOH }\end{array}$ & $\begin{array}{c}\text { Aqueous } \\
\text { Starch }\end{array}$ & Hydrogel & $\mathrm{K}^{+}$adsorbed & $\begin{array}{c}\mathrm{Ca}^{2+} \\
\text { adsorbed } \\
\end{array}$ & Assignment of peaks \\
\hline \multicolumn{6}{|c|}{ Wave numbers in $\mathrm{cm}^{-1}$} \\
\hline--- & --- & --- & 3753 & 3730 & $\mathrm{M}-\mathrm{O}-\mathrm{H}$, stretching $(\mathrm{M}=\mathrm{K}, \mathrm{Ca})$ \\
\hline 3367 & 3460 & 3460 & 3452 & 3450 & $\mathrm{O}-\mathrm{H}$ stretching \\
\hline 2950 & --- & 2900 & 2926 & 2940 & $\mathrm{C}-\mathrm{H}$ stretching \\
\hline--- & --- & --- & 2372 & 2368 & B-M stretching $(\mathrm{M}=\mathrm{K}, \mathrm{Ca})$ \\
\hline 2088 & 2079 & --- & --- & --- & $\mathrm{H}-\mathrm{O}-\mathrm{H}$ liberation for free water \\
\hline 1635 & 1635 & 1633 & 1649 & 1639 & $\mathrm{H}-\mathrm{O}-\mathrm{H}$ bending of bound water \\
\hline 1433,1315 & 1390 & --- & 1467,1429 & --- & $\mathrm{C}-\mathrm{H}$ bending \\
\hline--- & --- & 1382 & 1384 & 1382 & B-O-C stretching (tetrahedral) \\
\hline 1093 & 1018 & 980 & 1014 & 1014 & $\mathrm{C}-\mathrm{O}$ stretching \\
\hline--- & --- & 600 & --- & --- & O-B-O stretching \\
\hline
\end{tabular}



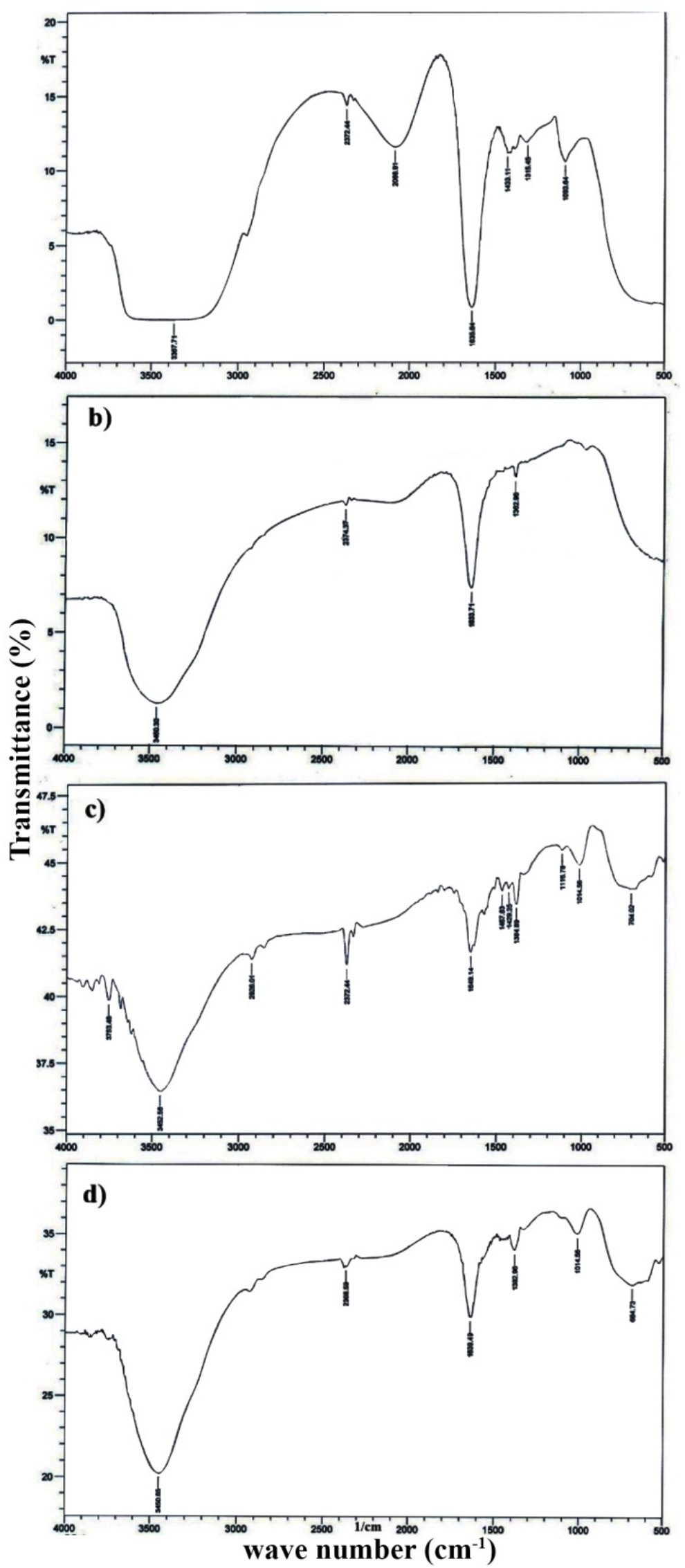

Fig. 3 - FTIR spectra (a) Aqueous PVOH, (b) PVOH-Starch borate hydrogel, (c) K ${ }^{+}$adsorbed PVOH-Starch borate hydrogel, (d) $\mathrm{Ca}^{2+}$ adsorbed PVOH-Starch borate hydrogel. 


\section{Mechanism of adsorption}

The interaction of borate ions with the hydroxyl groups of polysaccharides, ${ }^{8,9}$ PVOH-Starch ${ }^{6,}$ 10,11 and PVOH-cellulose $\mathrm{e}^{12}$ was reported. The interaction with borax, create cross-linked units utilizing hydroxyl groups of both $\mathrm{PVOH}$ and starch forming $\mathrm{PVOH}-$ starch borate hydrogel. The possible reaction between PVOH-Starch blend and borax was shown in Scheme 1.

The excess negative charge on $\mathrm{BO}_{4}{ }^{-}$units along with the presence of pores in the hydrogel made it suitable for the caging of ions. Thus, adsorption of $\mathrm{M}^{+}$proceeds with the interaction of $\mathrm{M}^{+}$with the $\mathrm{BO}_{4}{ }^{-}$units in PVOH-Starch borate hydrogel which later on continue with the filling of ions in pores present in hydrogel up to the saturation level of PVOH-Starch borate hydrogel replacing water molecules that persist in the pores of hydrogel. ${ }^{22}$ Similarly $\mathrm{M}^{2+}$ associates two $\mathrm{BO}_{4}^{-}$units of PVOHStarch borate hydrogel. The interaction of $\mathrm{K}^{+}$and $\mathrm{Ca}^{2+}$ ions in $\mathrm{PVOH}-\mathrm{Starch}$ borate hydrogel is shown in Scheme 2.

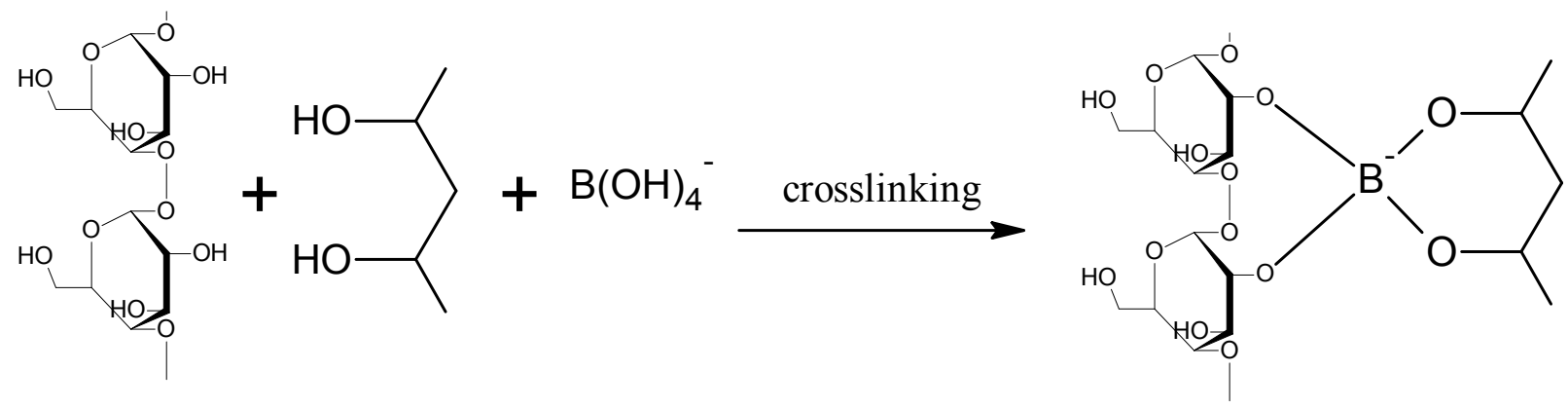

Scheme 1 - The possible reaction between PVOH-Starch blend and borax.

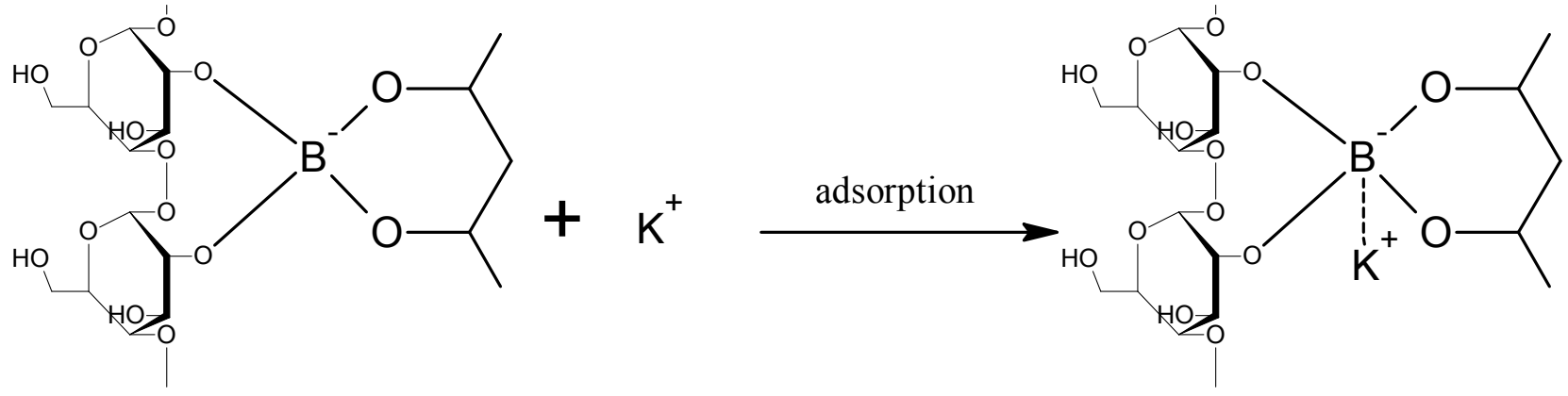

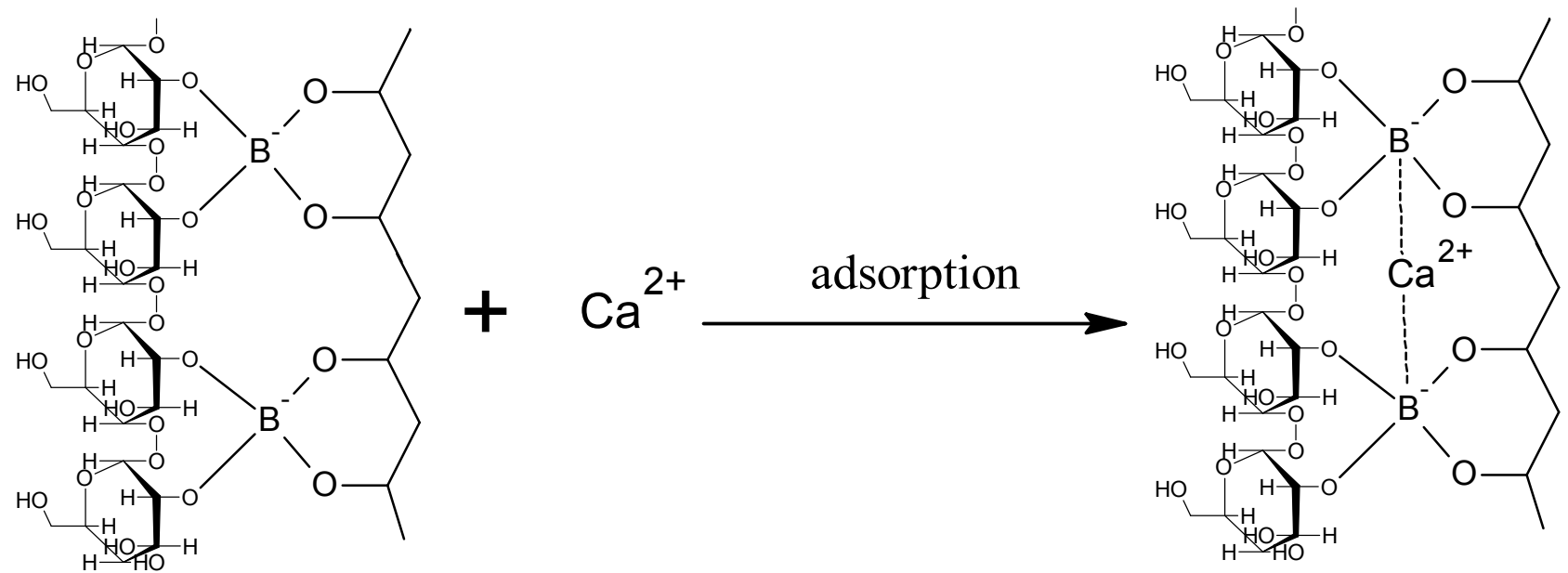

Scheme 2 - The interaction of $\mathrm{K}^{+}$and $\mathrm{Ca}^{2+}$ ions in PVOH-Starch borate hydrogel. 


\section{EXPERIMENTAL}

Glasswares of Pyrex-A quality were used. Chemicals include polymers: poly(vinyl alcohol) $\left(\mathrm{CH}_{2}-\mathrm{CH}-\mathrm{OH}\right)_{\mathrm{n}}$ and starch $\left(\mathrm{C}_{6} \mathrm{H}_{10} \mathrm{O}_{5}\right)_{\mathrm{n}}$; crosslinking agent: borax $\mathrm{Na}_{2} \mathrm{~B}_{4} \mathrm{O}_{7} \cdot 10 \mathrm{H}_{2} \mathrm{O}$ (99\% pure, E. Merck); electrolyte: lithium chloride, sodium chloride, potassium chloride, magnesium chloride and calcium chloride (99.9\% pure E. Merck). Deionized water with conductivity $0.06 \mu{\mathrm{S} . \mathrm{cm}^{-1}}^{-1}$ and reagents: silver nitrate, hydrochloric acid and sodium hydroxide (99\% pure, E. Merck) were used. Adsorption studies were carried out at $303 \mathrm{~K}$ for which thermostatic bath (circulator, model YCW-0.1 Taiwan) was used to maintain temperature.

$\mathrm{PVOH}$ and starch are dissolved in deionized water at $80 \pm 1^{\circ} \mathrm{C}$ and $100 \pm 1^{\circ} \mathrm{C}$, respectively, with continuous stirring to prepare $\left(5\right.$ g.dL $\left.{ }^{-1}\right)$ solution. PVOH-Starch borate hydrogel was prepared by mixing 1:1 $\mathrm{PVOH}$ :starch by weight and stirred until a homogeneous blend was obtained after which 0.05 mol. $\mathrm{L}^{-1}$ borax solution was added to blend in the ratio $4: 1$ blend: borax by volume with vigorous stirring until a homogeneous hydrogel was obtained.

Electrolytes of different concentration were prepared by dissolving definite amount in deionized water to obtain solutions in the range of $20-80$ g.L $\mathrm{L}^{-1}$.

Adsorption was carried out- using $(4.0 \pm 0.1 \mathrm{~g}) \mathrm{PVOH}-$ Starch borate hydrogel in a sintered glass cell having $(25.0 \pm 0.1 \mathrm{~mL})$ electrolyte for two hours. After two hours remaining electrolyte was analyzed by ion-exchange chromatography and argentometry for detection of the amount of adsorbed cations and anions, respectively. The obtained data were used for isotherm study.

\section{CONCLUSIONS}

Isotherms for the adsorption of electrolytes in PVOH-borate hydrogels were studied. The indulgence of starch in polymeric hydrogel enhanced the adsorption capacity and favored adsorption of large cations. The applicability of isotherm was decided on the basis of linear regression coefficient $R^{2}$ values. Lower $R^{2}$ values of Langmuir isotherms deny the chemisorption nature of adsorption process. Adsorption followed Freundlich, Temkin and D-R isotherms which conveyed that adsorption of electrolyte in $\mathrm{PVOH}-$ Starch borate hydrogel is physicosorption in nature along with involvement of interaction of electrolyte with $\mathrm{BO}_{4}^{-}$units and pores present in $\mathrm{PVOH}$ hydrogel. The peak around $1380 \mathrm{~cm}^{-1}$ confirmed the crosslinking of PVOH hydrogels and appearance of new peaks confirmed the association of metals ions in PVOH hydrogel.

Acknowledgement: Author (R. Saeed) acknowledges the research grant provided by Dean Faculty of Science, University of Karachi.

\section{REFERENCES}

1. J. BeMiller and R. Whistler, "Starch: Chemistry and Technology" Elsevier Inc, 2009.

2. N. Tudorachi, C.N. Cascaval, M. Rusu and M. Pruteanu, Polym. Test., 2000, 19, 785-799.

3. N. A. Azahari, N. Othman and H. Ismail, J. Phys. Sci., 2011, 22, 15-31.

4. A. A. Aydina and V. Ilberg, Carbohydr Polym., 2016, 136, 441-448.

5. M. A. L. Russo, R. Truss and P. J. Halley, Carbohydr. Polym., 2009, 77, 442-448.

6. B. Sreedhar, M. Sairam, D. K. Chattopadhyay, P. A. S. Rathnam, and D. V. M. Rao, J. Appl. Polym. Sci., 2005, 96, 1313-1322.

7. B. Balakrishnan and A. Jayakrishnan, Biomaterials, 2005, 26, 3941-3951.

8. I. Ali, S. U. Rehman, S. H. Ali and A. Javaid, J. Appl. Polym. Sci., 2013, 128, 3672-3677.

9. S. Gao, J. Guo and K. Nishinari, Carbohydr. Polym., 2008, 72, 315-325.

10. S. Widiarto, J. Sains. Tek., 2005, 11, 51-57.

11. S. Maiti, D. Ray and D. Mitra, J. Polym. Environ., 2012, 20, 749-759.

12. J. Han, T. Lei and Q. Wu, Cellulose, 2013, 20, 2947-2958.

13. S. Spoljaric, A. Salminen, N. D. Luong and J. Seppala, Eur. Polym. J., 2014, 56, 105-117.

14. Y. Dou, B. Zhang, M. He, G. Yin, Y. Cui and I. N. Savina, Polymers, 2015, 7, 580-591.

15. E. R. Kenawy, E. A. Kamoun, M. S. M Eldin and M. A. E. Meligy, Arab J. Chem., 2014, 7, 372-380.

16. X. Han, S. Chen and X. Hu, Desalination, 2009, 240, 21-26.

17. K. Y. Foo and B. H. Hameed, Chem. Eng. J., 2010, 156, $2-10$.

18. A. O. Dada, A. P. Olalekan, A. M. Olatunya and O. Dada, IOSR J. Appl. Chem., 2012, 3, 38-45.

19. A. U. Itodo and H. U. Itodo, Life Sci. J., 2010, 7, 31-39.

20. C. A. Cozzolino, G. Campanella, H. Tureb, R. T. Olsson and S. Farris, Carbohydr. Polym., 2016, 143, 179-187.

21. R. Saeed and Z. U. Abdeen, Int. J. Sci. Technol., 2013, 3, 132-142.

22. Z. Abdeen and R. Saeed, Polym. Sci. Ser. A., 2016, 58, 689-696. 